\title{
Interaction of steroid receptor coactivators and estrogen receptors in the human placenta
}

\author{
Seung Chul Kim,*, Mee-Na Park2,*, Young Joo Lee', Jong Kil Joo' and Beum-Soo An² \\ 'Department of Obstetrics and Gynecology, Biomedical Research Institute, Pusan National University \\ School of Medicine, Busan, Republic of Korea \\ 2Department of Biomaterials Science, College of Natural Resources \& Life Science/Life and Industry \\ Convergence Research Institute, Pusan National University, Republic of Korea \\ (*Kim and Park contributed equally to this work)
}

Correspondence should be addressed to B-S An

Email

anbs@pusan.ac.kr

\begin{abstract}
Female sex steroid hormones such as estrogen and progesterone have a pivotal role in maintaining pregnancy in human and animals. Especially, estrogen exerts specific effects on the cardiovascular system and angiogenesis, and thus affects significantly on placentation. Although the functions of estrogen have been emphasized during pregnancy, their signaling pathways in the placenta have not been fully understood. In this study, estrogen signaling was evaluated according to gestational age. Human placenta samples were collected and divided into early preterm $(n=10)$, late preterm $(n=18)$, and term $(n=20)$ groups. First, serum estrogen concentration and corticotropinreleasing hormone $(C R H)$ mRNA expression, which is known as gestation clock gene, were increased following gestation age in our experimental condition, as we expected. Next, the expression of estrogen receptors (ERs) and steroid receptor coactivators (SRCs) in the placenta was evaluated. ER $\alpha$ (ESR1) and ER $\beta$ (ESR2) were expressed highly at term period compared with early preterm. In addition, SRC family including SRC1, SRC2, and SRC3 was expressed in the human placenta, and the levels of SRC1, SRC2, and SRC3 were increased in the placenta at the late stage of gestation. The interaction of ERs with SRCs was also examined, which was significantly enhanced at term period. In the immunostaining results, it was indicated that ERs and SRCs were all dominantly expressed in syncytiotrophoblast cells. These results suggested that SRC1, SRC2, and SRC3 were expressed and interact with ERs highly at the late stage of gestation, and may amplify the signaling of estrogen in the placenta to maintain pregnancy.
\end{abstract}

\author{
Journal of Molecular \\ Endocrinology \\ (2016) 56, 239-247
}

\section{Introduction}

The placenta is a specialized organ during pregnancy, which in combination with fetal membranes and amniotic fluid supports normal growth and development of the fetus. The placenta has a hemochorial villus, whereby maternal blood comes into direct contact with placental trophoblast cells and allows an intimate relationship with the developing embryo (Moore et al. 2015). The placental membrane is made of four layers, a maternal facing syncytiotrophoblast layer, a cytotrophoblast cell layer, connective tissue of the villus, and maternal endothelium lining the fetal capillaries (Gude et al. 2004). However, the cytotrophoblast cell layer of the villus becomes attenuated and disappears after approximately

Published by Bioscientifica Ltd 
20 weeks. Subsequently, in most chorionic villi, the membrane consists of three layers and becomes extremely thin in some areas such that the syncytiotrophoblast directly contacts the fetal capillary endothelium. Thus, in these positions, the maternal and fetal blood comes into very close proximity (as little as 2-4 $\mathrm{mm}$ ) (Gude et al. 2004).

The main functions of the placenta can be categorized under the headings of transport and metabolism, protection, and endocrine functions. For transport, the placenta provides oxygen, water, carbohydrates, amino acids, lipids, vitamins, minerals, and other nutrients to the fetus, whereas removes carbon dioxide and other waste products (Gude et al. 2004). The placenta also metabolizes numerous substances and releases metabolic products into maternal and/or fetal circulations. It also helps to protect the fetus against certain toxic molecules, infections, and maternal diseases. For endocrine function, the placenta releases hormones into both the maternal and fetal circulations to affect pregnancy, metabolism, fetal growth, and parturition. The endocrine factors produced by the placenta include estrogen, progesterone, chorionic gonadotropin, placental lactogen, placental growth hormone, and many others (Gude et al. 2004, Lehrer et al. 1990).

During human pregnancy, the placenta produces large amounts of estrogen. Estrogen exerts a wide variety of effects on cellular growth, development, and differentiation. The physiological effects of estrogen include important regulatory functions within the reproductive systems of both females and males, which are related to mammary gland development and differentiation as well as regulation of the hypothalamic-gonadal axis (Pepe \& Albrecht 1995). During pregnancy, estrogen regulates a sequence of events leading to initiation of labor (Gibb et al. 2006), biosynthesis of progesterone, and placental transfer mechanisms that modulate maturation of the fetal reproductive system (Pepe \& Albrecht 1995). Furthermore, estrogen stimulates angiogenesis, which is a critical process for placental function, by regulating vascular endothelial growth factor (VEGF) and growth of endothelial cells in the placenta. Therefore, abnormal estrogen levels and angiogenesis in the placenta are associated with complications such as preeclampsia and preterm delivery (Albrecht \& Pepe 2010).

Estrogen acts by binding to its receptor, estrogen receptor (ER). ER exists in two main forms, ER $\alpha$ (ESR1) and ER $\beta$ (ESR2), which have distinct tissue-specific expression patterns (Mueller \& Korach 2001). ER $\alpha$ and ER $\beta$ are nuclear steroid hormone receptors with similarities in terms of ligand-binding and nuclear DNA-binding regions (Arnal et al. 2007, Luksha \& Kublickiene 2009). ER $\alpha$ and ER $\beta$ are encoded by separate genes, ESR1 and ESR2, respectively, located at different chromosomal locations, and numerous mRNA splice variants exist for both receptors in both diseased and normal tissues (Herynk \& Fuqua 2004). In the 'classical' pathway, estrogen binds to ER to regulate the transcription of target genes in the nucleus by binding to estrogen response element (ERE) in the promoters of target genes and by recruiting coregulatory proteins such as coactivators or corepressors (McKenna \& O’Malley 2002).

Several classes of coactivators have been identified and shown to be essential in estrogen responsiveness (McKenna \& O'Malley 2002). The major coregulators involved in estrogen signaling are the p160 steroid receptor coactivator (SRC) family, consisting of SRC1/NCoA1, GRIP1/TIF2/SRC2, and pCIP/RAC3/ACTR/AIB1/TRAM1/ SRC3, which enhance transcriptional activation and recruit other cofactors possessing histone acetyl transferase activity (Leo \& Chen 2000). SRCs interact with ER and enhance estrogen signals. Coactivators such as SRCs are fundamental to the proper function of reproductive events such as fertility (Mukherjee et al. 2007), uterine growth, blastocyst implantation (Mukherjee et al. 2006), and mammary gland development (Xu et al. 2000). The pleiotropic actions of SRCs make them attractive candidates as biomarkers for a multitude of pathologies. In relation to cancer, SRC3 overexpression results in aggressive breast and lung cancers (Osborne et al. 2003, Wang et al. 2010), SRC2 mutations are associated with prostate cancer metastases (Taylor et al. 2010), and SRC1 overexpression leads to early resistance to breast cancer therapy (Redmond et al. 2009). Furthermore, the significance of SRC activity in shaping the metabolic landscape suggests that they may be etiological predictors for numerous metabolic diseases.

Despite their fundamental actions in reproductive organs, no study has examined the expression of SRCs in the human placenta. The objective of this study was to define the expression, localization, and possible function of SRCs in the human placenta according to gestational age. Interactions between SRCs and ERs were also explored to elucidate the actions of estrogen in the placenta during pregnancy.

\section{Materials and methods}

\section{Tissue and plasma collection and processing}

This study was approved by the Institutional Review Board of the Pusan National University Hospital Clinical Trials Center (H-1302-005-015) and all participants gave written informed consent. Placental tissue and plasma samples were obtained from pregnant women who met

Published by Bioscientifica Ltd. 
the following inclusion criteria: 1) singleton pregnancy, 2) normal pregnancy at the time of sample collection, and 3) healthy women with no preexisting clinical conditions such as diabetes, hypertension, or autoimmune disease. The placental samples were divided into early preterm, late preterm, and term groups after onset of labor. The early preterm period was determined to be 22-29 weeks of gestation, which is clinically important because preterm delivery frequently happens during this period, whereas the late preterm period was determined to be 30-36 weeks of gestation. The term placenta group was collected from a gestational age of 37-40 weeks. The clinical characteristics of sample groups are given in Table 1 .

\section{Measurement of blood estradiol concentration}

From each volunteer, blood was collected in plastic tubes under aseptic conditions with EDTA as an anticoagulant and then centrifuged in order to separate plasma. The plasma was stored at $-70^{\circ} \mathrm{C}$, and the sample was slowly thawed at room temperature. Plasma estradiol concentrations were measured using an estradiol-ELISA kit No. 582251 (Cayman, Ann Arbor, MI, USA) following the manufacturer's protocol.

\section{Quantitative real-time PCR}

Total RNA was extracted using Trizol reagent (Invitrogen), according to the manufacturer's protocol. The concentration of total RNA was measured using a spectrophotometer. First-strand complementary DNA (cDNA) was prepared from total RNA $(3 \mu \mathrm{g})$ by reverse transcription (RT) using M-MLV reverse transcriptase (Invitrogen) and random primers (9-mers; TaKaRa Bio). Quantitative real-time PCR (Q-PCR) was performed with a cDNA template $(2 \mu \mathrm{L})$ and $2 \times$ Power SYBR Green $(6 \mu \mathrm{L}$; ТОҮОВО Co., Osaka, Japan) containing specific primers. The primer sequences for $\beta$-actin, namely CRH,

Table 1 Clinical characteristics of pregnancies

\begin{tabular}{|c|c|c|c|}
\hline & $\begin{array}{l}\text { Early preterm } \\
\qquad(n=10)\end{array}$ & $\begin{array}{l}\text { Late preterm } \\
\qquad(n=18)\end{array}$ & $\begin{array}{l}\text { Term } \\
(n=20)\end{array}$ \\
\hline $\begin{array}{l}\text { Gestational age } \\
\text { (weeks) }\end{array}$ & $27.5 \pm 4.7$ & $34.2 \pm 8.2$ & $38.4 \pm 1.1$ \\
\hline Birth weight (g) & $887.0 \pm 312.5$ & $2316.1 \pm 570.7$ & $3167.0 \pm 268.8$ \\
\hline $\begin{array}{l}\text { Systolic BP } \\
(\mathrm{mmHg})\end{array}$ & $111.0 \pm 11.0$ & $107.8 \pm 8.1$ & $108.0 \pm 7.7$ \\
\hline $\begin{array}{l}\text { Diastolic BP } \\
(\mathrm{mmHg})\end{array}$ & $73.0 \pm 8.2$ & $67.8 \pm 8.1$ & $68.5 \pm 7.5$ \\
\hline Parity & $0.6 \pm 1.0$ & $0.7 \pm 0.8$ & $0.7 \pm 0.6$ \\
\hline Gravidity & $2.4 \pm 1.3$ & $2.5 \pm 1.5$ & $2.2 \pm 1.0$ \\
\hline BMI $\left(\mathrm{kg} / \mathrm{m}^{2}\right)$ & $23.1 \pm 2.6$ & $25.7 \pm 3.4$ & $25.0 \pm 1.6$ \\
\hline
\end{tabular}

ER $\alpha$, ER $\beta$, SRC1, SRC2, and SRC3, are given in Table 2. Q-PCR was carried out for 40 cycles using the following parameters: denaturation at $95^{\circ} \mathrm{C}$ for $15 \mathrm{~s}$, followed by annealing and extension at $70^{\circ} \mathrm{C}$ for $60 \mathrm{~s}$. Fluorescence intensity was measured at the end of the extension phase of each cycle. The threshold value for the fluorescence intensity of all samples was set manually. The reaction cycle at which PCR products exceeded this fluorescence intensity threshold during the exponential phase of PCR amplification was considered to be the threshold cycle (CT). The expression of the target gene was quantified relative to that of $\beta$-actin, a ubiquitous housekeeping gene, based on comparison of CTs at constant fluorescence intensity.

\section{Immunoprecipitation and western blotting analysis}

Protein samples were extracted with Pro-prep solution (iNtRON Biotechnology, Korea) by following the manufacturer's protocol. Immunoprecipitation was performed based on a previous study (An et al. 2006). Briefly, $200 \mu \mathrm{g}$ of protein was precleared with protein $A / G$ agarose beads (Santa Cruz Biotechnology) for $1 \mathrm{~h}$ at $4^{\circ} \mathrm{C}$, followed by exposure to antibodies together with beads overnight. Immunoprecipitates were then washed three times, eluted in $3 \times$ sodium dodecyl sulfate (SDS) loading buffer, and processed for western blotting. Twenty microgram of protein was loaded for input. The proteins were separated by $8 \%$ SDS-polyacrylamide gel electrophoresis (SDS-PAGE) and transferred onto nitrocellulose membranes (Daeillab Service $\mathrm{Co}$, Seoul, Korea). The membranes were then blocked for $2 \mathrm{~h}$ with $5 \%$ skim milk (Difco, Sparks, MD, USA) in phosphate-buffered saline (PBS) with 0.05\% Tween-20 (PBS-T). After blocking, the membranes were incubated with anti-ER $\alpha$ rabbit (Santa Cruz Biotechnology, diluted 1:500), anti-ER $\beta$ rabbit (Santa Cruz Biotechnology, diluted 1:500),

Table 2 Primer sequences for real-time PCR analyses

\begin{tabular}{|c|c|c|c|}
\hline Gene name & Primer & Sequence $\left(5^{\prime}-3^{\prime}\right)$ & $\begin{array}{c}\text { Fragment } \\
\text { (bp) }\end{array}$ \\
\hline \multirow[t]{2}{*}{$\beta$-actin } & Forward & GGACTTCGAGCAAGAGATGG & 234 \\
\hline & Reverse & AGCACTGTGTTGGCGTACAG & \\
\hline \multirow[t]{2}{*}{$\mathrm{CRH}$} & Forward & GGCAGGGCCCTATGATTTAT & 178 \\
\hline & Reverse & TCCCCTCAGTCTCTCAATGG & \\
\hline \multirow[t]{2}{*}{$E R \alpha$} & Forward & AGCACCCTGAAGTCTCTGGA & 153 \\
\hline & Reverse & GATGTGGGAGAGGATGAGGA & \\
\hline \multirow[t]{2}{*}{$E R \beta$} & Forward & AAGAAGATTCCCGGCTTTGT & 173 \\
\hline & Reverse & TCTACGCATTTCCCCTCATC & \\
\hline \multirow[t]{2}{*}{ SRC1 } & Forward & CATGGTCAGGCAAAAACCTT & 195 \\
\hline & Reverse & GCTTGCCGATTTTGGTGTAT & \\
\hline \multirow[t]{2}{*}{$S R C 2$} & Forward & AATGCATCAGCAACAGCAAG & 225 \\
\hline & Reverse & ATAAGTGGGCTCTGGGGAGT & \\
\hline \multirow[t]{2}{*}{$S R C 3$} & Forward & ACATGGGAGTCCTGGTCTTG & 206 \\
\hline & Reverse & AAGTCCCCACACCTTCACTG & \\
\hline
\end{tabular}

Published by Bioscientifica Ltd 
anti-SRC1 mouse (Thermo Fisher Scientific diluted 1:500), anti-SRC2 mouse (Thermo Fisher Scientific, diluted 1:1000), and anti-SRC3 mouse antibodies (Santa Cruz Biotechnology, diluted 1:1000) for overnight, followed by HRP-conjugated anti-rabbit and anti-mouse secondary antibodies (diluted 1:2000) in 5\% skim milk with PBS-T for $1 \mathrm{~h}$. Luminol reagent (Bio-Rad) was used to visualize the antibody binding. Each blot was then stripped by incubation with $2 \%$ SDS and $100 \mathrm{mM}$ mercaptoethanol in $62.5 \mathrm{mM}$ Tris- $\mathrm{HCl}(\mathrm{pH} 6.8)$ for $30 \mathrm{~min}$ at $50-60^{\circ} \mathrm{C}$. The membranes were subsequently probed with antibody against actin (Santa Cruz Biotechnology, diluted 1:2000) as an internal control. The blots were scanned using Gel Doc 1000, version 1.5 (Bio-Rad), and band intensities were normalized to $\beta$-actin levels.

\section{Histological analysis}

The placental tissues were fixed with 10\% formalin, embedded in paraffin wax, routinely processed, and then sectioned into $4 \mu \mathrm{m}$ thick slices. The tissue sections were then stained with hematoxylin \& eosin (SigmaAldrich). For immunohistochemistry, the sections were deparaffinized and rehydrated through a graded series of alcohol using standard procedures. Endogenous peroxidase activity was quenched using a $10 \mathrm{~min}$ incubation step with $3 \% \mathrm{H}_{2} \mathrm{O}_{2}$ in $\mathrm{MeOH}$. Nonspecific binding reactions were blocked by incubation with $10 \%$ bovine serum albumin and incubated with primary antibody solution overnight at $4^{\circ} \mathrm{C}$. The tissue sections were then rinsed three times for $2 \mathrm{~min}$, each in PBS while slowly warming to room temperature, followed by incubation with second antibody for $10 \mathrm{~min}$. The primary antibody was detected using a Polink-2 Plus HRP DAB kit (GBI Labs, Mukilteo, WA, USA). The images of the tissue were captured at $40 \times$ using a model BX50F-3 optical microscope (Olympus).

\section{Statistical analysis}

The results are presented as the mean \pm standard deviation (s.D.). Data were analyzed using Sigma Plot 10.0 (Systat Software Inc, San Jose, CA, USA). The $P$-values $<0.05$ were considered to be statistically significant.

\section{Results}

\section{Plasma estradiol concentration and CRH mRNA expression level during gestational age}

For the initial experiment, plasma estradiol concentration during gestational period was measured. The plasma samples were obtained from 23 normal pregnant females, and estradiol concentration ranged between 2990 and $12,650 \mathrm{pg} / \mathrm{mL}$ with a median value of $6092 \mathrm{pg} / \mathrm{mL}$. Estradiol plasma concentrations gradually increased with higher gestational age (Fig. 1A). The mean values of estradiol were $4279 \mathrm{pg} / \mathrm{mL}$ (early preterm), $6898 \mathrm{pg} / \mathrm{mL}$ (late preterm), and $7738 \mathrm{pg} / \mathrm{mL}$ (term). Next, we examined the expression of corticotrophin-releasing hormone $(C R H)$, which is a wellknown biomarker of gestational age in the human placenta. As expected, transcriptional levels of $C R H$ increased according to the gestational age. The expression levels increased to 2.6- and 7.9-fold in the late preterm and term groups, respectively, compared with early preterm (Fig. 1B).

\section{Expression of ER $\alpha$ and ER $\beta$ in placenta during gestation}

For the next experiment, we evaluated expression of both ER $\alpha$ and ER $\beta$ in placental tissues by Q-PCR (Fig. 2). As shown in Fig. $2 \mathrm{~A}$ and $\mathrm{B}$, mRNA levels of both $E R \alpha$ and $E R \beta$ were significantly elevated in the term placenta compared with early preterm placenta by 2.3 - and 1.8-fold, respectively. The protein levels of ERs were also analyzed by western blot assay, and their photographic figures are represented in Fig. 2C. The results indicate that ER $\alpha$ and ER $\beta$ protein levels in the term gestational placenta were dramatically greater than those in early preterm (Fig. 2D and E), which was consistent with the results obtained for mRNA levels. The uniformity of the $\beta$-actin (internal standard) bands in these western blots further confirms that equal amounts of protein were loaded onto the gels.

\section{Expression of SRCs in placenta during gestation}

Expression levels of $S R C$ mRNA in the placenta were examined by Q-PCR. SRC1 and SRC2 mRNA levels were
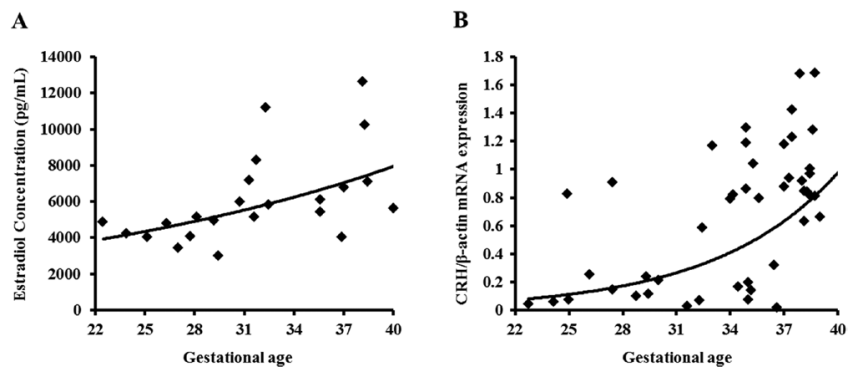

Figure 1

Plasma estradiol concentration and mRNA levels of $C R H$ in human placenta according to gestational age. Plasma estradiol concentration $(\mathrm{pg} / \mathrm{mL})(A)$ and mRNA levels of $\mathrm{CRH}(B)$ were measured and represented. Data are expressed as the mean \pm S.D. ${ }^{*} P<0.05$ compared with the early preterm group.

Published by Bioscientifica Ltd. 
A
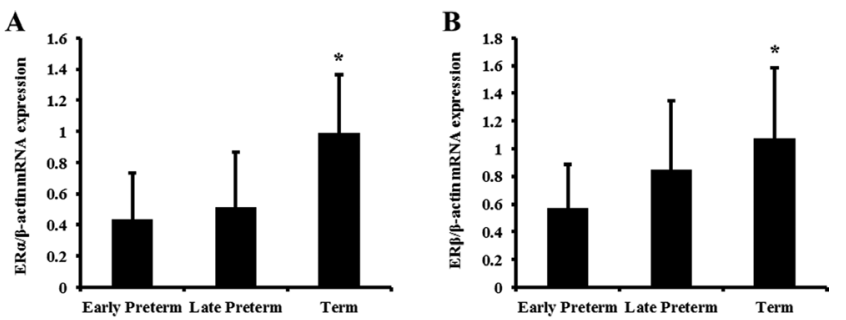

C

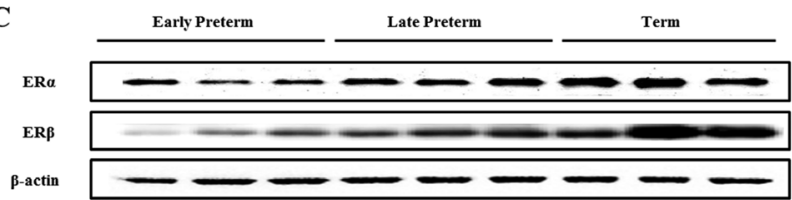

D
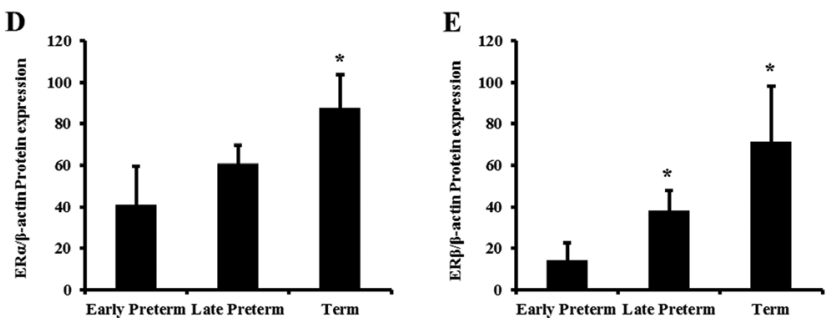

Figure 2

The mRNA and protein levels of $E R \alpha$ and $E R \beta$ in human placenta according to gestational age. Total mRNA and proteins were harvested from the human placenta after onset of labor. Transcriptional levels of $E R \alpha(A)$ and $\operatorname{ER} \beta(B)$ were analyzed by Q-PCR depending on gestational age. Proteins from at least six different samples were examined and quantified for graphs, and the representative samples were shown in (C). The values for $E R \alpha(D)$ and $E R \beta(E)$ were represented as schematic graphs. Total mRNA and protein expression levels were normalized to that of $\beta$-actin. Data are expressed as the mean \pm S.D. ${ }^{*} P<0.05$ compared with the early preterm group.

elevated in the term placenta compared with early preterm placenta up to 2- and 2.8-fold, respectively (Fig. 3A and B). The expression levels of SRC3 mRNA slightly increased, although the change was not significant (Fig. 3C). Protein expression of SRC1, SRC2, and SRC3 was also examined by western blot assay (Fig. 3D) and represented as schematic graphs (Fig. 3E, F, and $\mathrm{G})$. Both SRC1 and SRC2 proteins were upregulated in the term placenta, which was similar to the mRNA levels. The protein levels of SRC3 showed similar pattern for SRC1 and SRC2 by increasing at term placenta 2.8- and 4.5 -fold compared with late preterm and early preterm.

\section{Correlation between ERs and SRCs in placenta according to gestational age}

To confirm the interaction between ER and SRCs proteins, we performed co-immunoprecipitation experiments. We immunoprecipitated total proteins from early preterm and term placenta using antibodies for SRC1, SRC2, and SRC3, and performed western blots for ER $\alpha$ and ER $\beta$. First, both ER $\alpha$ and ER $\beta$ interacted with SRC1 more strongly at term period compared with early preterm period (Fig. 4A). The basal interactions of SRC1 with ER $\alpha$ and ER $\beta$ were not significantly different in early preterm. However, interaction of SRC1 with ER $\alpha$ was drastically stronger than that with ER $\beta$ at term period, suggesting that SRC1 was more closely associated with ER $\alpha$ than ER $\beta$ during this period. Next, interaction of ERs with SRC2 and SRC3 was evaluated (Fig. 4B and C). SRC2 and SRC3 strongly interacted with both ER $\alpha$ and ER $\beta$ at term compared with early preterm. In contrast to SRC1, interactions of SRC2 and SRC3 with ER $\alpha$ and ER $\beta$ at term period were not significantly altered.

\section{Immunohistochemical detection of ERs and SRCs in the placenta}

To further explore the expression patterns of ERs and SRCs in placental tissues, formalin-fixed tissues were subjected to immunohistochemical analysis using antibodies specific for ERs and SRCs as described in the Materials and methods section. The morphology of placental tissue was first confirmed by H\&E staining (Fig. 5A). The cytotrophoblast section was surrounded withalayer of syncytiotrophoblasts, which is a general morphological feature of the placenta. As shown in Fig. 5B, tissue was stained only with secondary antibody in order to test the specificity of the immunoreaction as a negative control. ER $\alpha$ and ER $\beta$ were localized to both cyto- and syncytiotrophoblast cells. However, signals were more dominant in the nuclei of syncytiotrophoblast cells (Fig. 5C and D). The expression patterns of SRC- 2 and -3 proteins were similar with those of ERs by localizing more at syncytiotrophoblast (Fig. 5F and G). The signal of SRC1 was strongly shown in the cytotrophoblast cell than any other antibody (Fig. 5E).

\section{Discussion}

During pregnancy, estrogen synthesized by the uteroplacental unit using steroid precursors from maternal and fetal adrenal glands plays a crucial role in maintaining pregnancy (Albrecht \& Pepe 1990, Magness 1998). Therefore, the plasma levels of estrogen are potentially useful for understanding the physiological cause of clinical complications. In this study, we measured the concentration of plasma estrogen during an experimental gestational period (22-40 weeks of gestation). Many studies have reported that serum estrogen levels increase

Published by Bioscientifica Ltd. 
A

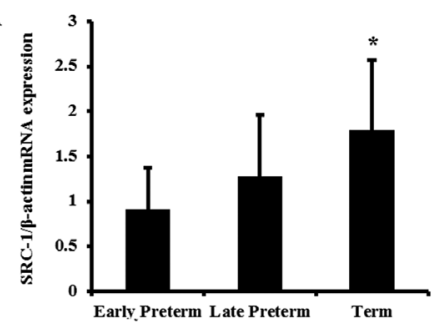

B

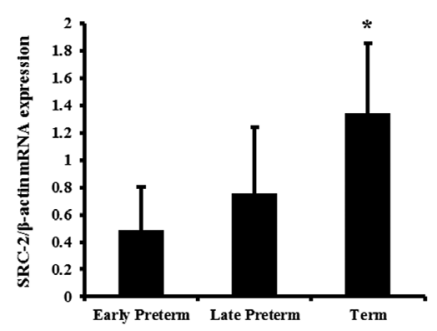

C

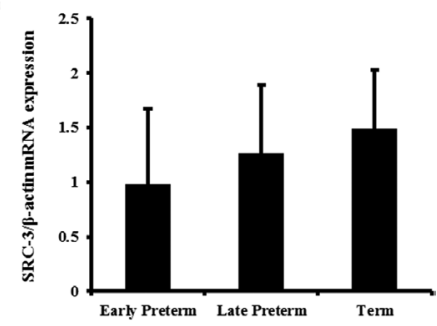

D

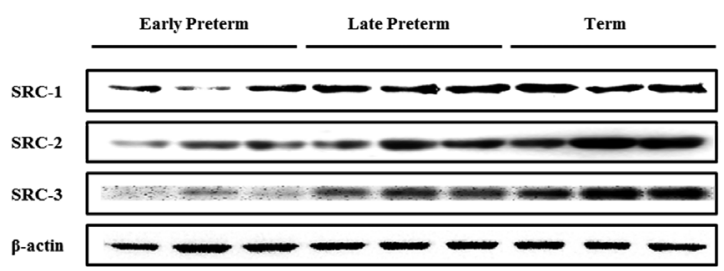

E

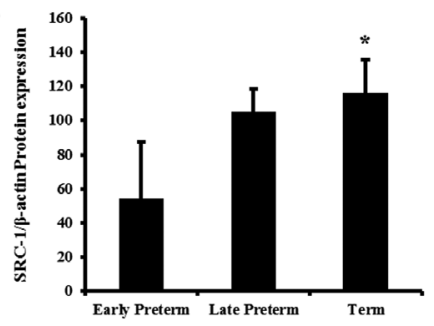

F

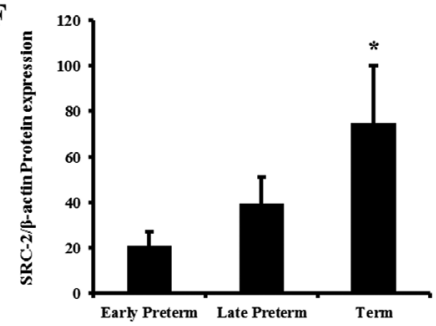

G

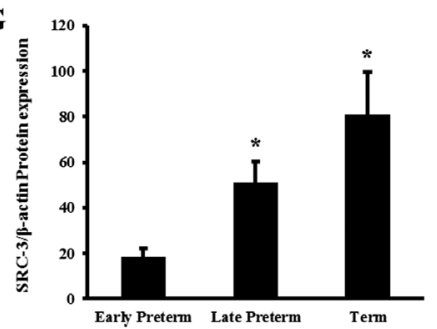

Figure 3

The mRNA and protein levels of SRCs in human placenta according to gestational age. Total mRNA and proteins were harvested from the human placenta after onset of labor. Transcriptional levels of SRC1 (A), SRC2 (B), and SRC3 (C) were analyzed by Q-PCR depending on gestational age. Proteins from at least six different samples were examined and quantified for graphs, and the representative samples were shown in (D). The values for SRC1 (E), SRC2 (F), and SRC3 (G) were represented as schematic graphs. Total mRNA and protein expression levels were normalized to that of $\beta$-actin. Data are expressed as the mean \pm S.D. ${ }^{*} P<0.05$ compared with the early preterm group.

progressively from 22 week of gestation to regulate placental growth (Mesiano 2001, You et al. 2006).

In this study, the experimental groups were separated by early preterm, late preterm, and term period. Depending on the period of gestation, estrogen may exert different functions. For example, during preterm, it is closely involved in the angiogenesis and growth of placenta, which is necessary for the growth of fetus. However, in term period, estrogen is associated with the preparation of delivery by regulating uterine contraction (Mesiano et al. 2002). To confirm this, our placenta samples were arranged according to gestational age, we examined the expression of $C R H$, which is proposed to regulate the placental clock and controls a cascade of physiological events leading to parturition (Smith et al. 2002). CRH is synthesized primarily in the paraventricular nucleus of the hypothalamus, whereas it is produced by the placenta during pregnancy. Placental CRH production increases dramatically over the course of normal human gestation (McLean et al. 1995), reaching levels at term observed only in the hypothalamic portal system (median eminence) during physiological stress (Lowry 1993). Abnormally accelerated rates or excessive levels of placental CRH are the significant risk factors for earlier onset of spontaneous birth (Holzman et al. 2001, Ng et al. 2002, Wadhwa et al. 2004). In our results, CRH expression progressively increased depending on gestation age, as expected, suggesting that our placental samples reflected proper gestational age.

Estrogen exerts its function via binding to its specific receptors, $\mathrm{ER} \alpha$ and $\mathrm{ER} \beta$, which play important roles in maintaining uteroplacental and systemic circulations during pregnancy (Byers et al. 2005). In a previous report, reduced $\mathrm{ER} \alpha$ expression caused by a single-nucleotide polymorphism was implicated in the pathogenesis of spontaneous abortion (Lehrer et al. 1990). Furthermore, a woman with prior preeclampsia also showed reduced risk of breast cancer, which is consistent with reduced ER

Published by Bioscientifica Ltd. 
A

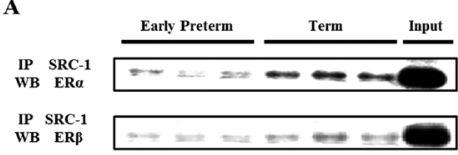

B

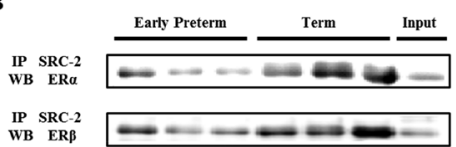

C

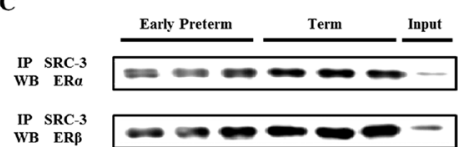

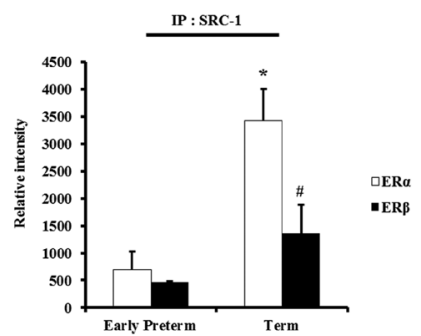
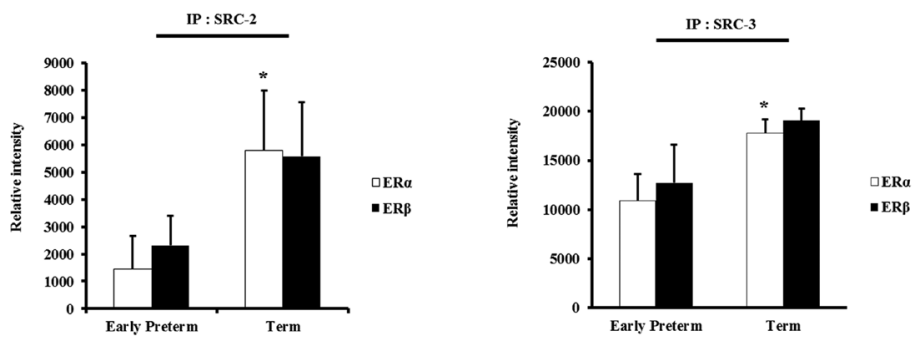

\section{Figure 4}

Interactions between ER and SRC proteins in human placenta according to gestational age. Proteins in the placenta were immunoprecipitated using anti-SRC1 (A), anti-SRC2, and anti-SRC3 (B) antibodies. The immunoprecipitates were then probed with anti-ER $\alpha$ and anti-ER $\beta$ antibodies, and values are represented as graphs. ${ }^{*} P<0.05$ compared with the control group; ${ }^{*}$ significant compared ER $\alpha$.

expression (Forman et al. 2005). ER $\alpha$ and ER $\beta$ are necessary for estrogen-mediated protection against vascular injury (Karas et al. 2001, Pare et al. 2002). In this study, transcriptional and translational levels of $\mathrm{ER} \alpha$ and $\operatorname{ER} \beta$ in the placenta increased at the late stage of gestation. Although many studies have focused on the concentration of estrogen, only one study examined ER expression in the human placenta. Specifically, only mRNA levels of $E R \alpha$ and $E R \beta$ in the placenta were tested from the first trimester to term (Fujimoto et al. 2005). The mRNA levels of both $E R \alpha$ and $E R \beta$ increased from the first to second trimester and then suddenly decreased until normal term delivery, which differs from our results. They also observed that the mRNA expression of estrogen-related receptors (ERRs), $E R R \alpha, E R R \beta$, and $E R R \gamma$, all gradually increased until term delivery. On the other hand, placental ER expression in rats has been shown to gradually decrease during gestation (Al-Bader 2006).

To understand estrogen-related signaling, interactions of ERs with their coregulators should be elucidated, because coregulators such as SRCs critically modulate initiation of ER/ERE transcription. Although the expression
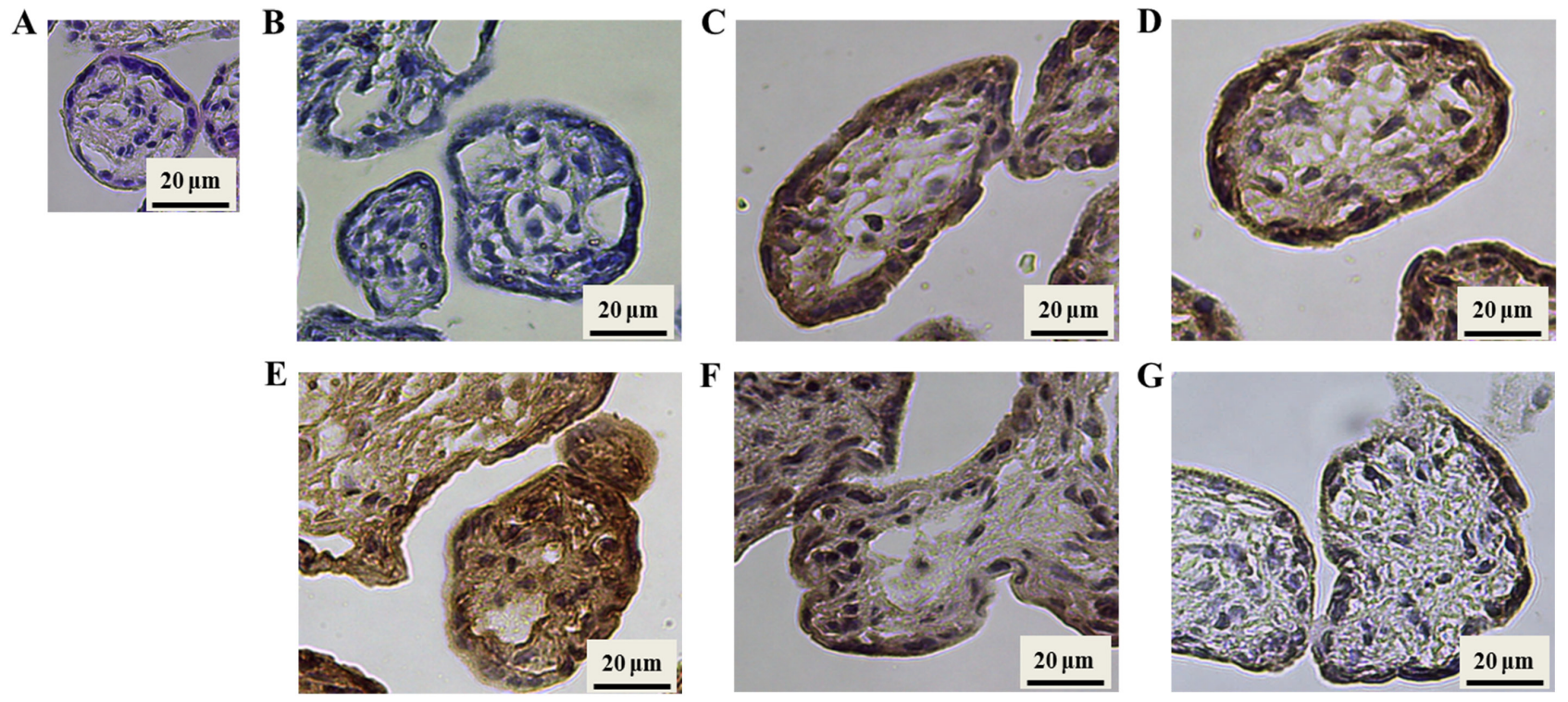

Figure 5

Immunostaining of ERs and SRCs in human placental tissue. Placental tissue was stained with H\&E to confirm placental morphology (A, 40x magnification). The section was stained only with secondary antibody as a negative control (B). To examine localization of each protein, tissues were stained with specific antibodies for ER $\alpha(C)$, ER $\beta(D)$, SRC1 (E), SRC2 (F), and SRC3 (G). A full colour version of this figure is available at http://dx.doi.org/10.1530/JME-15-0248. 
and regulation of SRC family proteins have been well established in other tissues such as the uterus and mammalian glands, they have not been explored in the placenta. We thus measured the mRNA levels of $S R C S$ in the placenta. First, $S R C 1, S R C 2$, and $S R C 3$ were all present in the human placenta. Specifically, mRNA expression levels of SRC1, SRC2, and SRC3 were enhanced in the term placenta compared with early preterm placenta, although the result of $S R C 3$ was not significant, but the protein levels of SRC1, SRC2, and SRC3 were upregulated in term placenta compared with early preterm placenta. These results indicate that SRC1, SRC2, and SRC3 may regulate estrogen signaling in the placenta and play pivotal roles during pregnancy.

We also evaluated the interactions between ERs and SRCs in the human placenta by immunoprecipitation assays. In the results, the signal of input was different among IP samples. The intensity of input in IP sample for SRC1 was stronger than SRC2 and SRC3. It may be due to the basal interaction of SRC1 with ERs, which was weaker than those of SRC2 and SRC3. The interactions of ERs with SRC1, SRC2, and SRC3 were significantly augmented in the term placenta. Interestingly, SRC1 interacted with ER $\alpha$ more than ER $\beta$ at term, whereas SRC2 and SRC3 did not show any change depending on the isoforms of ER. Numerous studies have shown that SRC and ER interactions are closely involved in the estrogen-mediated pathway. In breast cancer cells, knockdown of SRC1 abolished estrogen-related signaling (Klinge 2000). Furthermore, another previous study showed that the fertility of both sexes is impaired in Src2-knockout mice. Specifically, male hypofertility was found to be due to defects in spermatogenesis and testicular degeneration, while that of female was because of placental hypoplasia, suggesting the possible critical function of SRC2 in the placenta (Gehin et al. 2002).

A recent report has shown that ER $\alpha$ and SRC1 proteins are expressed in distinct subsets of cells within the epithelium of the estrogen-responsive rat mammary gland (Shim et al. 1999). Results from Src1-null mice revealed decreased mammary responsiveness to estrogen (Xu et al. 1998), suggesting that ER $\alpha$ and SRC1 have distinct patterns of expression and function within the mammary gland. In contrast, ER $\alpha$ and SRC1 were colocalized to the rat uterine epithelium (Shim et al. 1999). Taken together, these results indicate that SRC1 plays a cell type-specific role in ER actions. To determine whether or not ERs are colocalized with SRCs, we performed immunohistochemistry analysis. ERs and SRCs were detected mainly in syncytiotrophoblasts but weakly in cytotrophoblasts, suggesting that ERs and SRCs may be associated.
In summary, our results demonstrate that estrogen signaling may be amplified by several pathways in the placenta during gestation. High levels of plasma estrogen that increased the expression of ERs and SRCs and stimulated the interactions between ERs and SRCs in the placenta are involved in this signaling. The amplified signaling of estrogen may stimulate the function and growth of placenta in the late stage of gestation to maintain pregnancy.

Declaration of interest

The authors declare that there is no conflict of interest that could be perceived as prejudicing the impartiality of the research reported.

\section{Author contribution}

B.S. An, and S.C. Kim initiated and designed the study and played a role in recruitment of patients and sample collection. M.N. Park contributed towards acquisition of data. B.S. An, M.N. Park, S.C. Kim, Y.J. Lee, and J.K. Joo were involved in analysis and interpretation of the data. M.N. Park drafted the manuscript. All authors contributed to the revision of the manuscript and approval of the final draft.

\section{Acknowledgments}

This study was supported by a Biomedical Research Institute Grant (2013-09), Pusan National University Hospital.

\section{References}

Al-Bader MD 2006 Estrogen receptors alpha and beta in rat placenta: Detection by RT-PCR, real time PCR and Western blotting. Reproductive Biology and Endocrinology 4 13. (doi:10.1186/1477-7827-4-13)

Albrecht ED \& Pepe GJ 1990 Placental steroid hormone biosynthesis in primate pregnancy. Endocrine Reviews 11 124-150. (doi:10.1210/ edrv-11-1-124)

Albrecht ED \& Pepe GJ 2010 Estrogen regulation of placental angiogenesis and fetal ovarian development during primate pregnancy. International Journal of Developmental Biology 54397. (doi:10.1387/ijdb.082758ea)

An B-S, Selva DM, Hammond GL, Rivero-Muller A, Rahman N \& Leung PC 2006 Steroid receptor coactivator-3 is required for progesterone receptor trans-activation of target genes in response to gonadotropin-releasing hormone treatment of pituitary cells. Journal of Biological Chemistry 281 20817-20824. (doi:10.1074/ jbc.M600743200)

Arnal J-F, Scarabin P-Y, Trémollières F, Laurell H \& Gourdy P 2007 Estrogens in vascular biology and disease: Where do we stand today? Current Opinion in Lipidology 18 554-560. (doi:10.1097/ MOL.0b013e3282ef3bca

Byers MJ, Zangl A, Phernetton TM, Lopez G, Chen Db \& Magness RR 2005 Endothelial vasodilator production by ovine uterine and systemic arteries: Ovarian steroid and pregnancy control of ERa and ERß levels. Journal of Physiology 565 85-99.

Forman MR, Cantwell MM, Ronckers C \& Zhang Y 2005 Through the looking glass at early-life exposures and breast cancer risk. Cancer Investigation 23 609-624. (doi:10.1080/07357900500283093)

Fujimoto J, Nakagawa Y, Toyoki H, Sakaguchi H, Sato E \& Tamaya T 2005 Estrogen-related receptor expression in placenta throughout

Published by Bioscientifica Ltd. 
gestation. Journal of Steroid Biochemistry and Molecular Biology 94 67-69. (doi:10.1016/j.jsbmb.2004.12.030)

Gehin M, Mark M, Dennefeld C, Dierich A, Gronemeyer H \& Chambon P 2002 The function of TIF2/GRIP1 in mouse reproduction is distinct from those of SRC-1 and p/CIP. Molecular and Cellular Biology 22 5923-5937. (doi:10.1128/MCB.22.16.5923-5937.2002)

Gibb W, Lye S \& Challis J 2006 Parturition. In Knobil and Neill's Physiology of Reproduction, 3rd Edn, pp 2925-2974. Eds JD Neill, TM Plant, DW Pfaff, et al. Philadelphia, PA, USA: Elsevier. (doi:10.1016/ B978-012515400-0/50060-9)

Gude NM, Roberts CT, Kalionis B \& King RG 2004 Growth and function of the normal human placenta. Thrombosis Research 114 397-407. (doi:10.1016/j.thromres.2004.06.038)

Herynk MH \& Fuqua SA 2004 Estrogen receptor mutations in human disease. Endocrine Reviews 25 869-898. (10.1210/er.2003-0010)

Holzman C, Jetton J, Siler-Khodr T, Fisher R \& Rip T 2001 Second trimester corticotropin-releasing hormone levels in relation to preterm delivery and ethnicity. Obstetrics \& Gynecology 97 657-663.

Karas RH, Schulten H, Pare G, Aronovitz MJ, Ohlsson C, Gustafsson J-A \& Mendelsohn ME 2001 Effects of estrogen on the vascular injury response in estrogen receptor a, $B$ (double) knockout mice. Circulation Research 89 534-539. (doi:10.1161/hh1801.097239)

Klinge CM 2000 Estrogen receptor interaction with co-activators and co-repressors. Steroids 65 227-251. (doi:10.1016/S0039128X(99)00107-5)

Lehrer S, Song H, Levine E, Dalton J, Savoretti P, Schachter B, Sanchez M \& Thung S 1990 Oestrogen receptor B-region polymorphism and spontaneous abortion in women with breast cancer. The Lancet 335 622-624. (doi:10.1016/0140-6736(90)90410-7)

Leo C \& Chen JD 2000 The SRC family of nuclear receptor coactivators. Gene 245 1-11. (doi:10.1186/s13052-016-0223-1)

Lowry P 1993 Corticotropin-releasing factor and its binding protein in human plasma. Ciba Foundation Symposium 172 108-115.

Luksha L \& Kublickiene K 2009 The role of estrogen receptor subtypes for vascular maintenance. Gynecological Endocrinology 25 82-95. (doi:10.1080/09513590802485038)

Magness RR 1998 Maternal cardiovascular and other physiologic responses to the endocrinology of pregnancy. Endocrinology of Pregnancy 9 507-539.

McKenna NJ \& O'Malley BW 2002 Minireview: nuclear receptor coactivators-an update. Endocrinology 143 2461-2465. (doi:10.1210/endo.143.7.8892)

McLean M, Bisits A, Davies J, Woods R, Lowry P \& Smith R 1995 A placental clock controlling the length of human pregnancy. Nature Medicine 1 460-463. (doi:10.1038/nm0595-460)

Mesiano S 2001 Roles of estrogen and progesterone in human parturition. Frontiers of Hormone Research 27 86-104. (doi:10.1159/000061038)

Mesiano S, Chan E-C, Fitter JT, Kwek K, Yeo G \& Smith R 2002 Progesterone withdrawal and estrogen activation in human parturition are coordinated by progesterone receptor a expression in the myometrium. Journal of Clinical Endocrinology \& Metabolism $\mathbf{8 7}$ 2924-2930. (doi:10.1210/jcem.87.6.8609)

Moore KL, Persaud TVN \& Torchia MG 2015 The Developing Human: Clinically Oriented Embryology. New York, NY, USA: Elsevier Health Sciences.

Mueller SO \& Korach KS 2001 Estrogen receptors and endocrine diseases: Lessons from estrogen receptor knockout mice. Current Opinion in Pharmacology 1 613-619.

Mukherjee A, Amato P, Allred DC, DeMayo FJ \& Lydon JP 2007 Steroid receptor coactivator 2 is required for female fertility and mammary morphogenesis: Insights from the mouse, relevance to the human. Nuclear Receptor Signaling 5 e011.
Mukherjee A, Soyal SM, Fernandez-Valdivia R, Gehin M, Chambon P, DeMayo FJ, Lydon JP \& O'Malley BW 2006 Steroid receptor coactivator 2 is critical for progesterone-dependent uterine function and mammary morphogenesis in the mouse. Molecular and Cellular Biology 26 6571-6583. (doi:10.1128/MCB.00654-06)

Ng P, Lam C, Lee C, Ma K, Fok T, Chan I \& Wong E 2002 Reference ranges and factors affecting the human corticotropin-releasing hormone test in preterm, very low birth weight infants. Journal of Clinical Endocrinology \& Metabolism 87 4621-4628. (doi:10.1210/ jc.2001-011620)

Osborne CK, Bardou V, Hopp TA, Chamness GC, Hilsenbeck SG Fuqua SA, Wong J, Allred DC, Clark GM \& Schiff R 2003 Role of the estrogen receptor coactivator AIB1 (SRC-3) and HER-2/neu in tamoxifen resistance in breast cancer. Journal of the National Cancer Institute 95 353-361.

Pare G, Krust A, Karas RH, Dupont S, Aronovitz M, Chambon P \& Mendelsohn ME 2002 Estrogen receptor-a mediates the protective effects of estrogen against vascular injury. Circulation Research 90 1087-1092. (doi:10.1161/01.RES.0000021114.92282.FA)

Pepe GJ \& Albrecht ED 1995 Actions of placental and fetal adrenal steroid hormones in primate pregnancy. Endocrine Reviews 16 608-648. (doi:10.1210/edrv-16-5-608)

Redmond AM, Bane FT, Stafford AT, McIlroy M, Dillon MF, Crotty TB, Hill AD \& Young LS 2009 Coassociation of estrogen receptor and p160 proteins predicts resistance to endocrine treatment; SRC-1 is an independent predictor of breast cancer recurrence. Clinical Cancer Research 15 2098-2106. (doi:10.1158/1078-0432.CCR-081649)

Shim W-S, DiRenzo J, DeCaprio JA, Santen RJ, Brown M \& Jeng M-H 1999 Segregation of steroid receptor coactivator-1 from steroid receptors in mammary epithelium. PNAS 96 208-213. (doi:10.1073/ pnas.96.1.208)

Smith R, Mesiano S \& McGrath S 2002 Hormone trajectories leading to human birth. Regulatory Peptides 108 159-164. (doi:10.1016/S01670115(02)00105-2)

Taylor BS, Schultz N, Hieronymus H, Gopalan A, Xiao Y, Carver BS, Arora VK, Kaushik P, Cerami E \& Reva B 2010 Integrative genomic profiling of human prostate cancer. Cancer Cell $\mathbf{1 8}$ 11-22.

Wadhwa PD, Garite TJ, Porto M, Glynn L, Chicz-DeMet A, Dunkel-Schetter C \& Sandman CA 2004 Placental corticotropinreleasing hormone $(\mathrm{CRH})$, spontaneous preterm birth, and fetal growth restriction: A prospective investigation. American Journal of Obstetrics and Gynecology 191 1063-1069. (doi:10.1016/j. ajog.2004.06.070)

Wang H, Zhang D, Wu W, Zhang J, Guo D, Wang Q, Jing T, Xu C, Bian X \& Yang K 2010 Overexpression and gender-specific differences of SRC-3 (SRC-3/AIB1) immunoreactivity in human nonsmall cell lung cancer: An in vivo study. Journal of Histochemistry \& Cytochemistry $\mathbf{5 8} 1121-1127$.

Xu J, Liao L, Ning G, Yoshida-Komiya H, Deng C \& O'Malley BW 2000 The steroid receptor coactivator SRC-3 (p/CIP/RAC3/AIB1/ACTR/ TRAM-1) is required for normal growth, puberty, female reproductive function, and mammary gland development. PNAS 97 6379-6384. (doi:10.1073/pnas.120166297)

Xu J, Qiu Y, DeMayo FJ, Tsai SY, Tsai M-J \& O’Malley BW 1998 Partial hormone resistance in mice with disruption of the steroid receptor coactivator-1 (SRC-1) gene. Science 279 1922-1925. (doi:10.1126/science.279.5358.1922)

You X, Yang R, Tang X, Gao L \& Ni X 2006 Corticotropin-releasing hormone stimulates estrogen biosynthesis in cultured human placental trophoblasts. Biology of Reproduction 74 1067-1072. (doi:10.1095/biolreprod.105.049361)

Received in final form 4 December 2015

Accepted 4 January 2016

Accepted Preprint published online 5 January 2016 http://jme.endocrinology-journals.org

DOI: 10.1530/JME-15-0248
(C) 2016 Society for Endocrinology Printed in Great Britain
Published by Bioscientifica Ltd. 